\title{
Extending and understanding the South West Western Australian rainfall record using a snowfall reconstruction from Law Dome, East Antarctica
}

Yaowen Zheng et al.

Correspondence to: Yaowen Zheng (yaowen.zheng@vuw.ac.nz)

The copyright of individual parts of the supplement might differ from the article licence. 


\section{Tests for normality}

Figure S1 shows CDFs for DSS snow accumulation, AWAP gridded rainfall and 15 BoM stations rainfall. All of these 17 CDFs are in agreement with their corresponding normal distributions with negligible biases. Not only are the shapes between the empirical and normal CDFs similar, but also the distances between them are negligible. This visual validation has shown

5 consistency with the results from one-sample KS tests that we cannot reject the null hypothesises that the data comes from normal distributions. Therefore, all of the rainfall data passes the normality tests. Therefore, we can apply the Pearson correlation coefficients and also perform parametric tests on any of the rainfall data. 

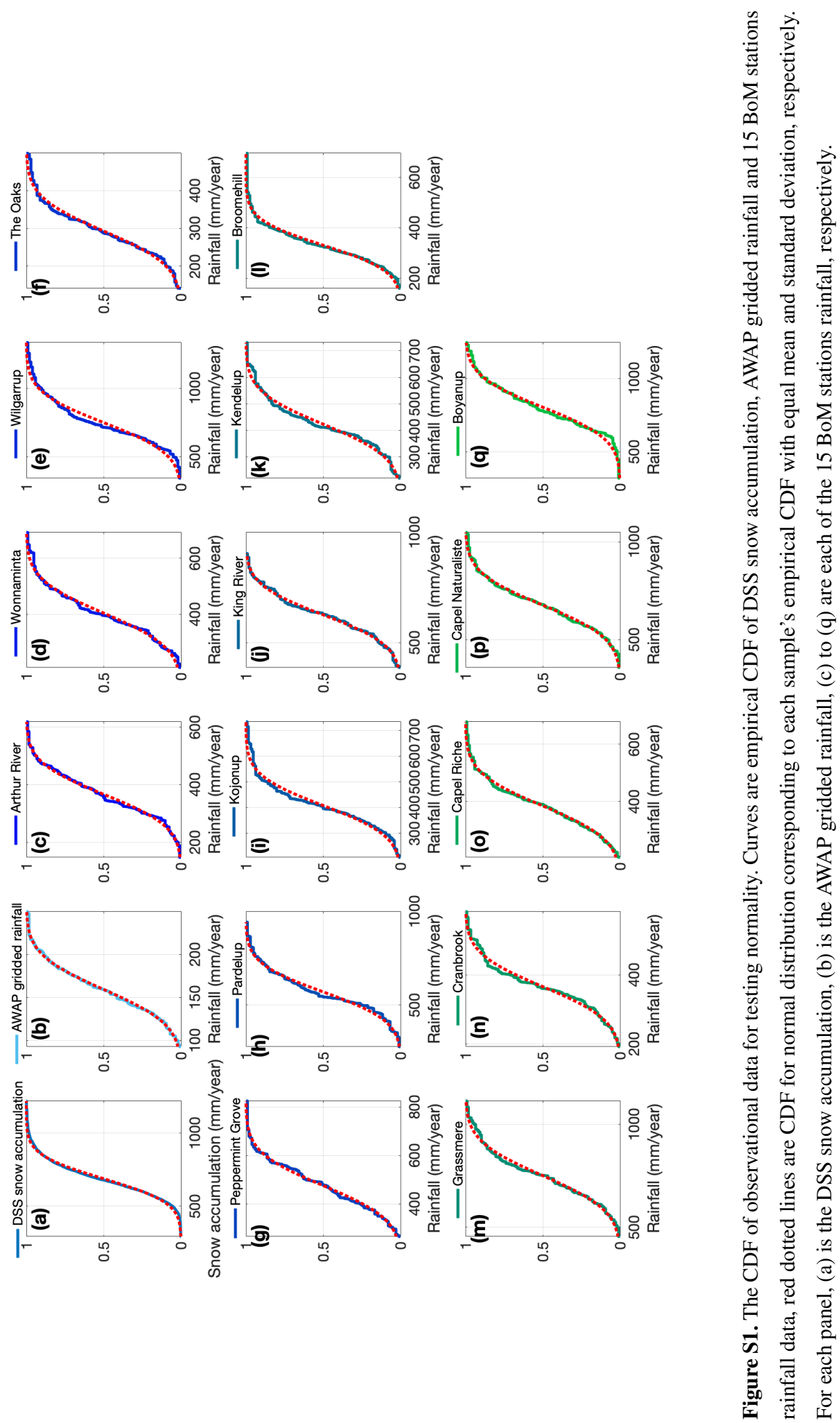

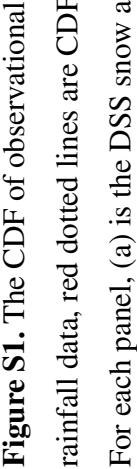




\section{Defining the window size for smoothing}

We test the effect of smoothing, using window sizes of 1-10 years, on the correlation between SWWA rainfall and DSS

10 accumulation data. We calculate the Pearson correlation coefficient, estimate the ESS (Equation 1) and calculate Student's t-statistic (Equation 2) for each window of the AWAP gridded rainfall and BoM stations rainfall. Figure S2(a) is the results of the Pearson correlation coefficient and the number of the grids that have statistically significant $(\mathrm{p}<0.05)$ correlations for the AWAP gridded rainfall. A six-year window maximizes the number of the grids (Figure S2a) with statistically significant ( $p$ $<0.05)$ correlations, and negligibly changes the magnitude of the correlation coefficient compared with the adjacent window

15 sizes (Figure S2a). Therefore, a six-year window is the optimal window size for moving average smoothing on the AWAP gridded rainfall.

The results of the 15 BoM stations show differences compared with the AWAP gridded rainfall. A two-year window maximizes the number of the stations (Figure S2b) with statistically significant $(p<0.05)$ correlations. But the correlation is relatively low compared with the larger window sizes (Figure S2b). The correlation increases as the window size increases

20 (Figure S2b). For consistency with the AWAP gridded rainfall, we also use six-year window to smooth the BoM stations rainfall. 

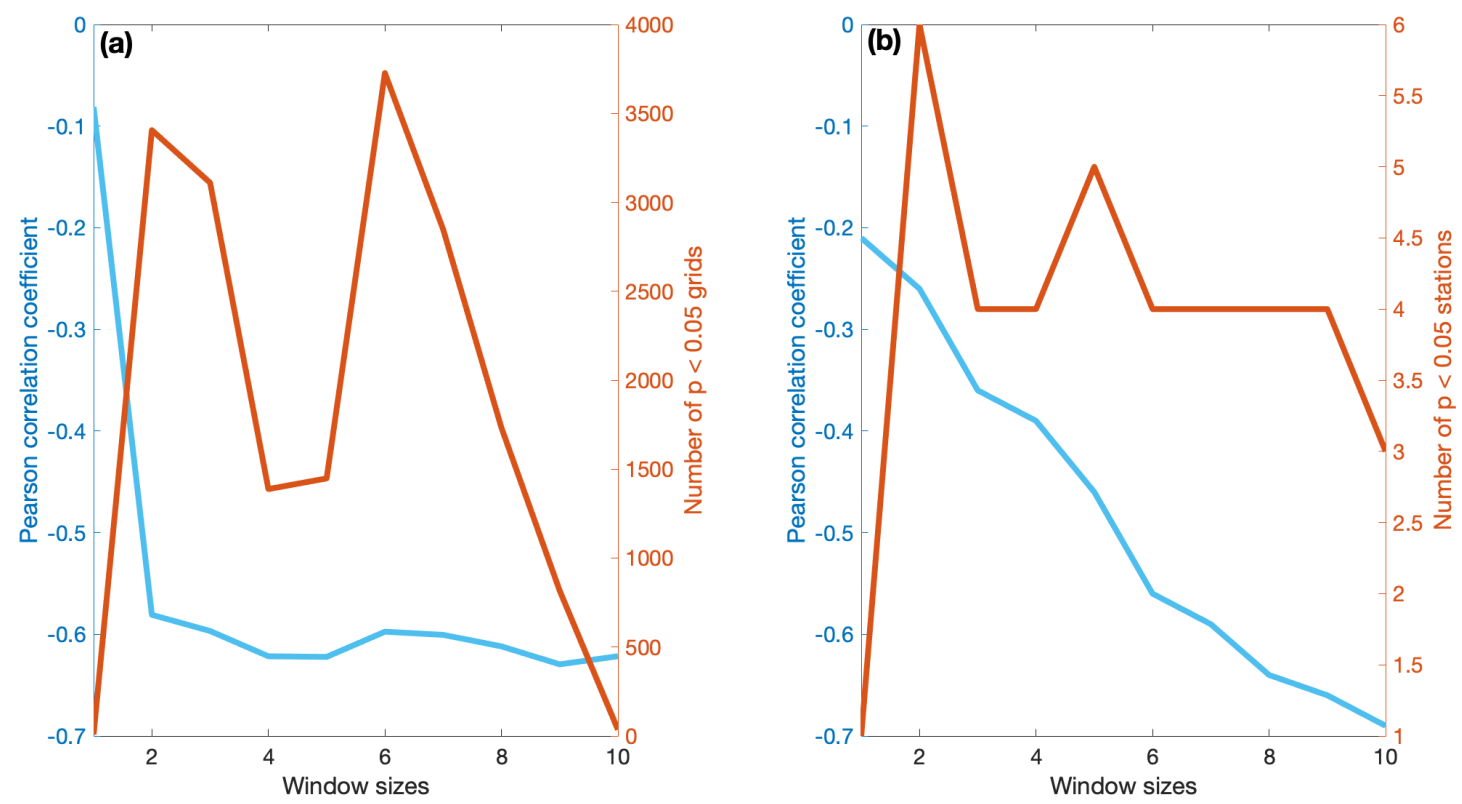

Figure S2. (a) Pearson correlation coefficient and the number of the statistically significant $(p<0.05)$ grids for AWAP rainfall data under different window sizes of moving average smoothing. (b) Pearson correlation coefficient and the number of the statistically significant ( $p<$ 0.05 ) stations for 15 BoM stations rainfall data under different window sizes of moving average smoothing. For both panels, blue lines and the left-hand side $y$-axis are the average of the Pearson correlation coefficient of the statistically significant $(\mathrm{p}<0.05)$ grids/stations, red lines and the right-hand side $y$-axis are for the number of the statistically significant $(\mathrm{p}<0.05)$ grids/stations. 


\section{Significance testing for 110 Local Government Areas}

We independently calculate the Pearson correlation coefficients and test their statistical significance for each Local Government Areas (LGAs), and then combine the areas which are statistically significant $(\mathrm{p}<0.05)$ to make the "MASK" region. Table S1

shows the results for each LGA. The rainfall data for each LGA is smoothed by using 6-year moving average smoothing (see section 2 about how to define the window size). The ESS ( $N_{6}^{e f f}$ ) and Student's t-statistic (for testing the statistical significance) are calculated by using Equation 1 and Equation 2.

Table S1: The table for all 110 Local Government Areas (LGAs) with their Pearson correlation coefficients $\left(r_{6}\right)$ and ESS $\left(N_{6}^{e f f}\right.$ ) (under 6-year moving average smoothing). For some LGAs, "-" means the area of this LGA is less than one grid area of the geospatial resolution of the AWAP data. The bold numbers of correlation are statistically significant $(\mathrm{p}<0.05)$.

\begin{tabular}{|c|c|c|c|c|c|}
\hline Local Government Area & $r_{6}$ & $N_{6}^{e f f}$ & Local Government Area & $r_{6}$ & $N_{6}^{e f f}$ \\
\hline Albany & -0.35 & 0.17 & Dalwallinu & -0.46 & 0.17 \\
\hline Armadale & -0.51 & 0.13 & Dandaragan & -0.44 & 0.14 \\
\hline Augusta Margaret River & -0.48 & 0.15 & Dardanup & -0.54 & 0.14 \\
\hline Bassendean & -0.48 & 0.15 & Denmark & -0.44 & 0.16 \\
\hline Bayswater & -0.45 & 0.15 & Donnybrook Balingup & -0.53 & 0.15 \\
\hline Belmont & -0.47 & 0.14 & Dowerin & -0.43 & 0.18 \\
\hline Beverley & -0.50 & 0.15 & Dumbleyung & -0.41 & 0.15 \\
\hline Boddington & -0.51 & 0.15 & Dundas & -0.31 & 0.21 \\
\hline Boyanup Brook & -0.53 & 0.17 & East Fremantle & - & - \\
\hline Bridgetown Greenbushes & -0.51 & 0.16 & Fremantle & -0.38 & 0.14 \\
\hline Brookton & -0.49 & 0.15 & Gingin & -0.46 & 0.14 \\
\hline Broomehill Tambellup & -0.45 & 0.15 & Gnowangerup & -0.42 & 0.15 \\
\hline Bruce Rock & -0.46 & 0.17 & Goomalling & -0.45 & 0.17 \\
\hline Bunbury & -0.55 & 0.14 & Gosnells & -0.48 & 0.14 \\
\hline Busselton & -0.49 & 0.15 & Greater Geraldton & -0.36 & 0.16 \\
\hline Cambridge & - & - & Harvey & -0.51 & 0.15 \\
\hline Canning & -0.46 & 0.14 & Inwin & -0.48 & 0.15 \\
\hline Capel & -0.55 & 0.14 & Joondalup & -0.47 & 0.14 \\
\hline Carnamah & -0.48 & 0.15 & Kalamunda & -0.50 & 0.14 \\
\hline Chapman Valley & -0.39 & 0.16 & Katanning & -0.51 & 0.15 \\
\hline Chittering & -0.50 & 0.14 & Kellerberrin & -0.42 & 0.19 \\
\hline Claremont & - & - & Kent & -0.45 & 0.15 \\
\hline Cockburn & -0.42 & 0.14 & Kojonup & -0.47 & 0.15 \\
\hline
\end{tabular}




\begin{tabular}{|c|c|c|c|c|c|}
\hline Collie & -0.53 & 0.15 & Kondinin & -0.44 & 0.19 \\
\hline Coorow & -0.46 & 0.15 & Koorda & -0.38 & 0.17 \\
\hline Corrigin & -0.45 & 0.16 & Kulin & -0.43 & 0.18 \\
\hline Cottsloe & - & - & Kwinana & -0.46 & 0.14 \\
\hline Cranbrook & -0.51 & 0.16 & Lake Grace & -0.45 & 0.16 \\
\hline Cuballing & -0.48 & 0.15 & Mandurah & -0.42 & 0.14 \\
\hline Cunderdin & -0.47 & 0.18 & Manjimup & -0.54 & 0.16 \\
\hline Melville & -0.42 & 0.14 & South Perth & - & - \\
\hline Merredin & -0.42 & 0.20 & Stirling & -0.45 & 0.15 \\
\hline Mingenew & -0.49 & 0.16 & Subiaco & - & - \\
\hline Moora & -0.48 & 0.16 & Swan & -0.49 & 0.15 \\
\hline Morawa & -0.39 & 0.16 & Tammin & -0.46 & 0.18 \\
\hline Mosman Park & - & - & Three Springs & -0.51 & 0.15 \\
\hline Mount Marshall & -0.40 & 0.16 & Toodyay & -0.46 & 0.15 \\
\hline Mukinbudin & -0.42 & 0.17 & Trayning & -0.36 & 0.19 \\
\hline Mundaring & -0.48 & 0.15 & Victoria Park & -0.44 & 0.14 \\
\hline Murray & -0.49 & 0.14 & Victoria Plains & -0.50 & 0.15 \\
\hline Nannup & -0.52 & 0.15 & Vincent & - & - \\
\hline Narembeen & -0.43 & 0.19 & Waggin & -0.43 & 0.16 \\
\hline Narrogin & -0.45 & 0.16 & Wandering & -0.53 & 0.14 \\
\hline Nedlands & -0.41 & 0.14 & Wanneroo & -0.48 & 0.14 \\
\hline Northam & -0.42 & 0.16 & Waroona & -0.49 & 0.15 \\
\hline Northampton & -0.36 & 0.15 & West Arthur & -0.54 & 0.15 \\
\hline Nungarin & -0.41 & 0.20 & Westonia & -0.34 & 0.20 \\
\hline Peppermint Grove & - & - & Wickepin & -0.45 & 0.15 \\
\hline Perenjori & -0.43 & 0.15 & Williams & -0.53 & 0.15 \\
\hline Perth & -0.42 & 0.15 & Wongan Ballidu & -0.45 & 0.17 \\
\hline Pingelly & -0.49 & 0.15 & Woodaniling & -0.49 & 0.15 \\
\hline Plantegenet & -0.47 & 0.16 & Wyalkatchem & -0.41 & 0.18 \\
\hline Quairading & -0.46 & 0.17 & Yalgoo & -0.18 & 0.17 \\
\hline Rockingham & -0.44 & 0.14 & Yilgran & -0.20 & 0.19 \\
\hline Serpentine Jarrahdale & -0.52 & 0.14 & York & -0.47 & 0.15 \\
\hline
\end{tabular}




\section{Significance testing and linear model construction for BoM stations}

Table S2 shows the results of significance testing for each of the 15 BoM rainfall stations. King River shows the statistically significant $(\mathrm{p}<0.05)$ correlation on the raw data. We have discussed in section 2 that 5 -year window maximizes the number of the stations with statistically significant $(\mathrm{p}<0.05)$ correlations. For consistence with AWAP gridded rainfall, we here also calculate and test the 6-year smoothing rainfall for $15 \mathrm{BoM}$ stations data. With 6-year moving average smoothing, the number of the stations that show statistical significance $(\mathrm{p}<0.05)$ rises to four, and also the correlations become stronger.

Figure S3 shows the scatter plot for each BoM stations which have statistically significant ( $<<0.05$, 6-year smoothing) correlation. The distributions of data all show negative trends. We also build linear models for each station. Table S3 shows the gradients, intervals and RMSE for each stations. For each of these four stations, the gradient is always negative (Table S3). Negative gradients show consistency with the results of the Pearson correlation coefficients that the $r_{6}$ for each of these four stations are statistically significant $(\mathrm{p}<0.05)$ negative $($ Table $\mathrm{S} 2)$, and also the negative trend distributions for these four stations (Figure S3).

Table S2. The ID and location for each of the $15 \mathrm{BoM}$ rainfall stations and their rainfall record periods with the calculated results of Pearson correlation coefficients and the estimated ESS. $r$ and $N^{e f f}$ are Pearson correlation coefficients and ESS for raw data. $r_{6}$ and $N_{6}^{e f f}$ are Pearson correlation coefficients and ESS for moving average smoothed data with 6-year window size.

\begin{tabular}{ccccccccc}
\hline Station & ID & Longitude & Latitude & $\mathrm{r}$ & $N^{e f f}$ & $r_{6}$ & $N_{6}^{\text {eff }}$ & Period (CE) \\
\hline Arthur River & 10505 & $117.03^{\circ} \mathrm{E}$ & $33.34^{\circ} \mathrm{S}$ & -0.11 & 121 & $\mathbf{- 0 . 5 5}$ & 19 & $1891-2015$ \\
Boyanup & 9503 & $115.73^{\circ} \mathrm{E}$ & $33.48^{\circ} \mathrm{S}$ & -0.18 & 114 & $\mathbf{- 0 . 6 2}$ & 16 & $1898-2013$ \\
Broomehill & 10525 & $117.64^{\circ} \mathrm{E}$ & $33.85^{\circ} \mathrm{S}$ & 0.01 & 122 & -0.35 & 21 & $1891-2015$ \\
Cape Naturaliste & 9519 & $115.02^{\circ} \mathrm{E}$ & $33.54^{\circ} \mathrm{S}$ & -0.16 & 110 & -0.40 & 16 & $1904-2015$ \\
Cranbrook & 10537 & $117.57^{\circ} \mathrm{E}$ & $34.30^{\circ} \mathrm{S}$ & -0.08 & 123 & $\mathbf{- 0 . 5 4}$ & 19 & $1891-2015$ \\
Cape Riche & 9520 & $118.75^{\circ} \mathrm{E}$ & $34.61^{\circ} \mathrm{S}$ & -0.12 & 117 & -0.01 & 19 & $1897-2015$ \\
Grassmere & 9551 & $117.76^{\circ} \mathrm{E}$ & $35.02^{\circ} \mathrm{S}$ & -0.07 & 109 & -0.39 & 16 & $1903-2015$ \\
Kendenup & 9561 & $117.63^{\circ} \mathrm{E}$ & $34.49^{\circ} \mathrm{S}$ & -0.15 & 113 & -0.42 & 14 & $1901-2015$ \\
King River & 9564 & $117.92^{\circ} \mathrm{E}$ & $34.94^{\circ} \mathrm{S}$ & $\mathbf{- 0 . 2 1}$ & 102 & -0.35 & 15 & $1904-2007$ \\
Kojonup & 10582 & $117.15^{\circ} \mathrm{E}$ & $33.84^{\circ} \mathrm{S}$ & 0.01 & 127 & -0.32 & 19 & $1885-2015$ \\
Pardelup & 9591 & $117.38^{\circ} \mathrm{E}$ & $34.64^{\circ} \mathrm{S}$ & -0.04 & 114 & -0.46 & 17 & $1900-2015$ \\
Peppermint Grove & 9594 & $119.36^{\circ} \mathrm{E}$ & $34.44^{\circ} \mathrm{S}$ & -0.18 & 107 & -0.13 & 31 & $1904-2015$ \\
The Oaks & 10636 & $117.67^{\circ} \mathrm{E}$ & $33.16^{\circ} \mathrm{S}$ & 0.02 & 104 & -0.31 & 17 & $1907-2012$ \\
Wilgarrup & 9619 & $116.02^{\circ} \mathrm{E}$ & $34.15^{\circ} \mathrm{S}$ & -0.11 & 112 & -0.40 & 16 & $1901-2014$ \\
Wonnaminta & 10658 & $116.99^{\circ} \mathrm{E}$ & $32.83^{\circ} \mathrm{S}$ & -0.15 & 109 & $\mathbf{- 0 . 5 5}$ & 16 & $1905-2015$ \\
\hline
\end{tabular}



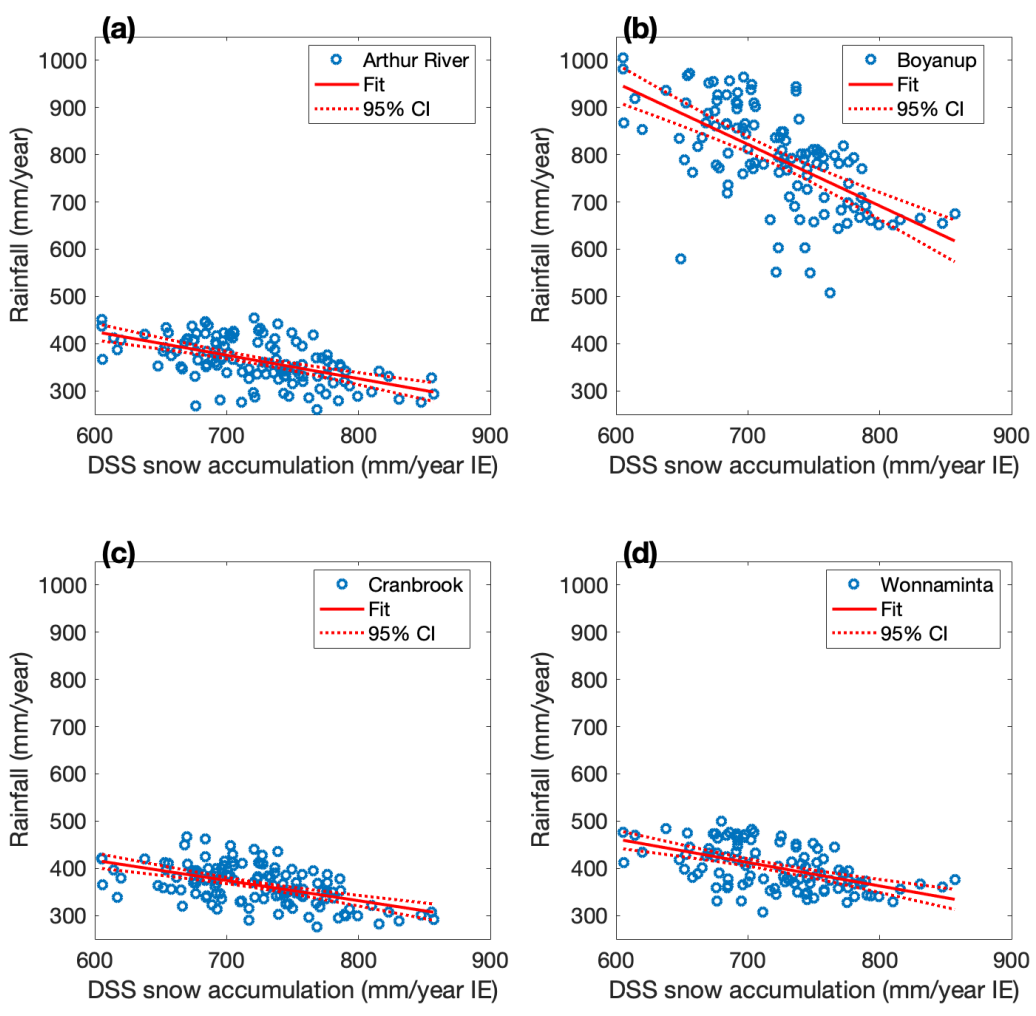

Figure S3. The scatter plor for four BoM stations rainfall that have statistically significant correlation (6-year smoothing, $p<0.05$ ) and their linear model with 95\% CI. For each panel, (a) is the Arthur River station, (b) is the Boyanup station, (c) is the Cranbrook station and (d) is the Wonnaminta station.

Table S3. The gradients and intervals of the linear models of each of the four BoM stations rainfall, with RMSE and periods.

\begin{tabular}{ccccc}
\hline Sample & Gradient & Interval & RMSE & Period (CE) \\
\hline Arthur River & {$[-0.63,-0.36]$} & {$[627,821]$} & $40.0 \mathrm{~mm}$ & $1891-2015$ \\
Boyanup & {$[-1.60,-1.00]$} & {$[1517,1952]$} & $83.5 \mathrm{~mm}$ & $1898-2013$ \\
Cranbrook & {$[-0.55,-0.31]$} & {$[588,759]$} & $35.1 \mathrm{~mm}$ & $1891-2015$ \\
Wonnaminta & {$[-0.64,-0.35]$} & {$[657,864]$} & $39.7 \mathrm{~mm}$ & $1905-2015$ \\
\hline
\end{tabular}




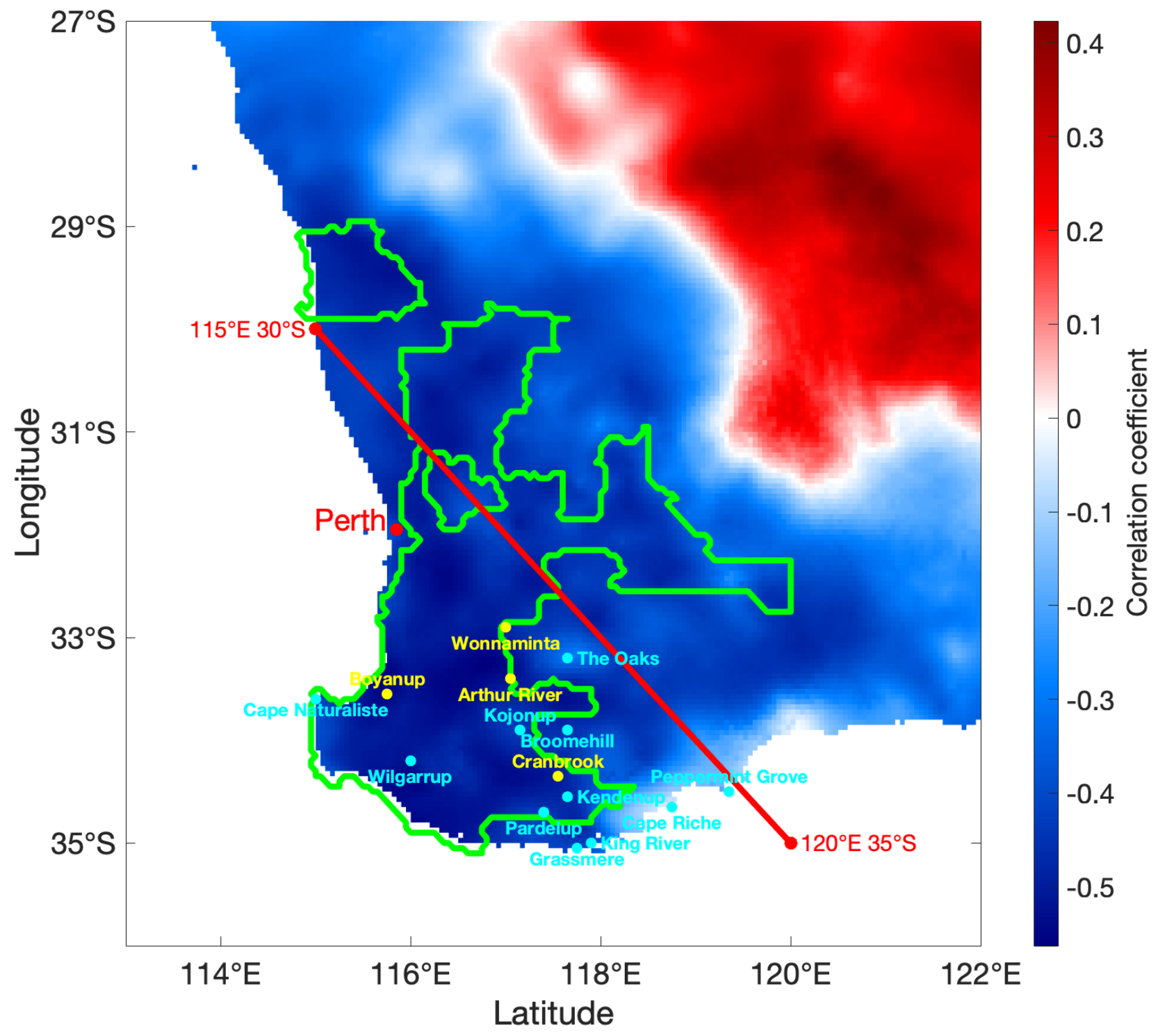

Figure S4. The correlation map for the southwest part of WA region for 6-year window AWAP rainfall and DSS snow accumulation from 1900 CE to 2015 CE. The outline area (green line) is the MASK region where the correlation is statistically significant ( $p<0.05$ ). Boyanup, Wonnaminta, Arthur River and Cranbrook are the four significant $(6$-year window, $p<0.05)$ stations. Blue "." marked stations are the other 11 non-significant stations. 
To validate the reconstruction, we have now performed a jackknife analysis over the period 1900-2015 for the mean AWAP data in the "MASK" region. Specifically:

1. We determine the autocorrelation length by calculating the autocorrelation at various time lags (e.g. lag-1, lag-2, lag-3, ..., lag- $6, \ldots$ ) on the unsmoothed observational data until the autocorrelation coefficient decreases to zero.

2. We use this autocorrelation length to perform a (modified) jackknife analysis.

3. For each subsample, we perform 6-year smoothing then calculate the correlation coefficient and construct the linear model.

The autocorrelation time-scale is 12 years. The results of the jackknife analysis are shown in the upper section of Table S4. The correlation coefficients for the individual members of the jackknife ensemble are tightly clustered around the value of 0.529 for the full period. Furthermore, the overlap between the $95 \%$ confidence intervals for the gradient and intercept indicates that the models derived for each jackknife ensemble member are statistically indistinguishable at the 5\% probability level. This demonstrates the robustness of the reconstruction technique.

To further explore whether the relationship between Law Dome accumulation and SWWA rainfall has changed during the current drought, the middle section of Table S4 repeats the jackknife analysis but increases the duration of the period omitted to 45 years. Although we find greater scatter in the values for the correlation coefficient, gradient and intercept, the $95 \%$ confidence intervals continue to overlap. We therefore find no evidence to suggest that the relationship between Law Dome accumulation and SWWA rainfall has changed.

We have verified that the CSIRO Mk3L runs pick up large-scale features that underpin the Law Dome end of the teleconnection by examining the correlation fields between mean sea level pressure and Law Dome precipitation in each member of OGSV (Figure S5). These show that the large scale circulation both matches the pattern identified in van Ommen and Morgan (2010) and is stable through time. This demonstrates that Law Dome accumulation is a robust proxy for the large-scale Southern Hemisphere circulation, which is a prerequisite for it to be a robust proxy for SWWA precipitation.

We calculate the mean of each region's nine cells for each member of ensemble and each ensemble mean and perform 6year smoothing for each series (for consistency), and then calculate the 100-year running correlation (Figure S6). The model simulations exhibit a lack of stationarity on decadal to centennal timescales, which should be considered when interpreting the reconstruction. The lack of a strong or consistent correlation between the simulated Law Dome and SWWA precipitation is not surprising, given the mechanism outlined in van Ommen and Morgan (2010). Correlation is essentially connected with periods of enhanced meridional flow which will be less apparent over extended periods which mix meridional and zonal modes of circulation. 
Table S4. The correlation coefficient between the smoothed ice core record and the mean of the AWAP rainfall in the "MASK" region. The three sections represents the results for a 12-year jackknife, a 45-year jackknife and the full period, respectively. x1 and Intercept are the coefficients for the linear model: Rain $=$ Snow $*(x 1 \pm 95 \%$ CI $)+$ Intercept $\pm 95 \%$ CI mm/year. The $95 \%$ confidence interval $(\mathrm{CI})$ is estimated by multiplying the standard error of the model by 1.96 .

\begin{tabular}{|c|c|c|c|c|}
\hline Section & Period & Correlation coefficient & $\mathrm{x} 1$ & Intercept (mm/year) \\
\hline \multirow{10}{*}{ 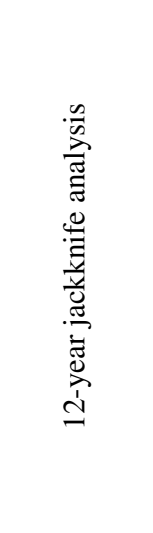 } & 1912-2015 & -0.536 & $-0.385 \pm 0.118$ & $667 \pm 85$ \\
\hline & 1900-1911 \& 1924-2015 & -0.513 & $-0.363 \pm 0.118$ & $651 \pm 85$ \\
\hline & $1900-1923 \&$ 1936-2015 & -0.532 & $-0.378 \pm 0.117$ & $662 \pm 85$ \\
\hline & $1900-1935 \& 1948-2015$ & -0.524 & $-0.405 \pm 0.128$ & $684 \pm 93$ \\
\hline & $1900-1947 \&$ 1960-2015 & -0.545 & $-0.407 \pm 0.122$ & $685 \pm 88$ \\
\hline & $1900-1959 \& 1972-2015$ & -0.499 & $-0.385 \pm 0.130$ & $671 \pm 94$ \\
\hline & $1900-1971 \&$ 1984-2015 & -0.506 & $-0.427 \pm 0.141$ & $699 \pm 101$ \\
\hline & $1900-1983 \&$ \& 1996-2015 & -0.492 & $-0.374 \pm 0.129$ & $662 \pm 92$ \\
\hline & $1900-1995$ \& 2008-2015 & -0.512 & $-0.356 \pm 0.116$ & $651 \pm 82$ \\
\hline & 1900-2007 & -0.593 & $-0.379 \pm 0.098$ & $670 \pm 71$ \\
\hline \multirow{4}{*}{ 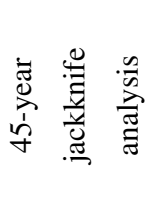 } & 1945-2015 & -0.511 & $-0.351 \pm 0.139$ & $635 \pm 103$ \\
\hline & 1900-1944 \& 1990-2015 & -0.414 & $-0.389 \pm 0.202$ & $672 \pm 144$ \\
\hline & $1900-1925$ \& 1971-2015 & -0.489 & $-0.403 \pm 0.170$ & $679 \pm 125$ \\
\hline & $1900-1970$ & -0.296 & $-0.193 \pm 0.147$ & $548 \pm 102$ \\
\hline Full period & 1900-2015 & -0.529 & $-0.389 \pm 0.114$ & $672 \pm 82$ \\
\hline
\end{tabular}



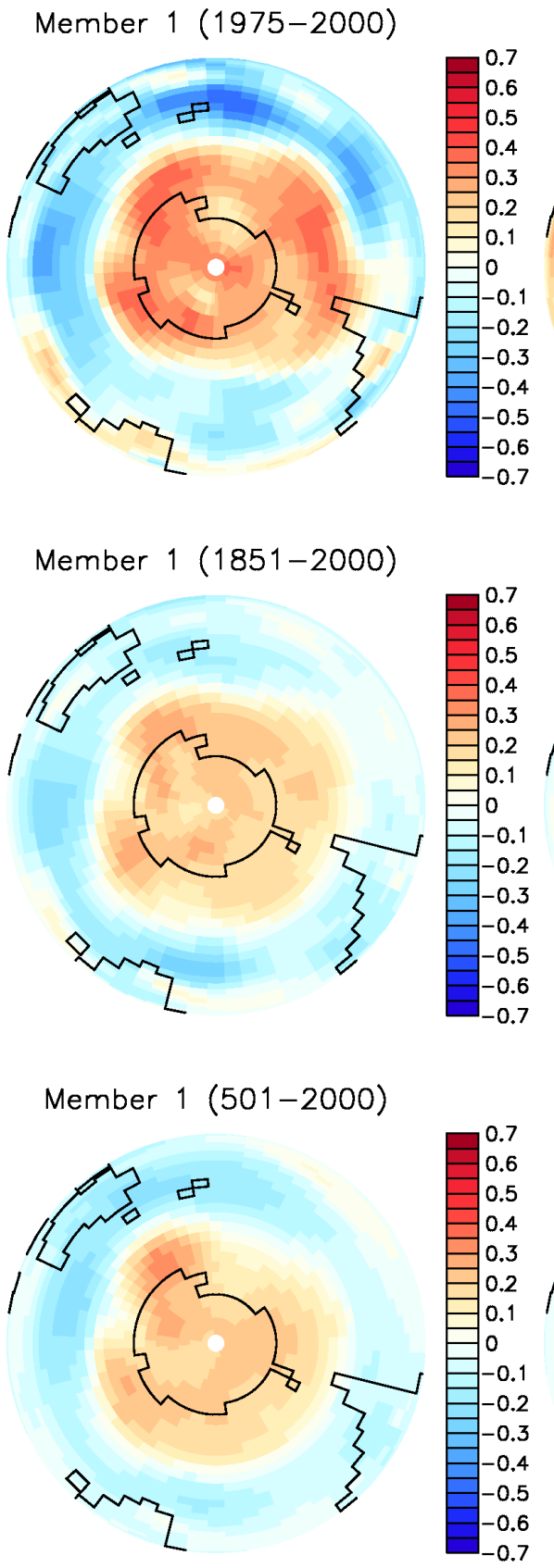

Member $2(1975-2000)$

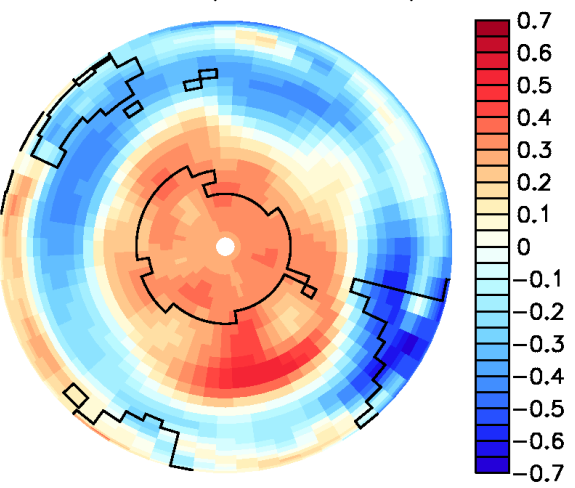

Member 2 (1851-2000)
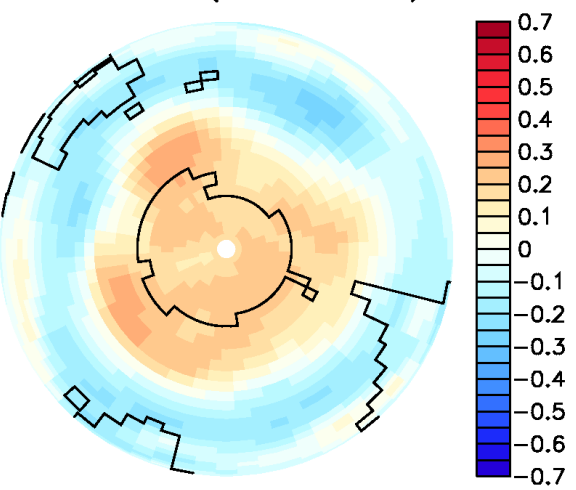

Member $2(501-2000)$
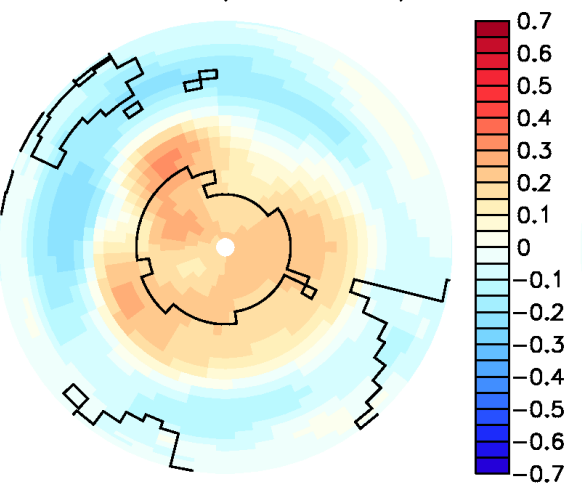

Member $3(1975-2000)$

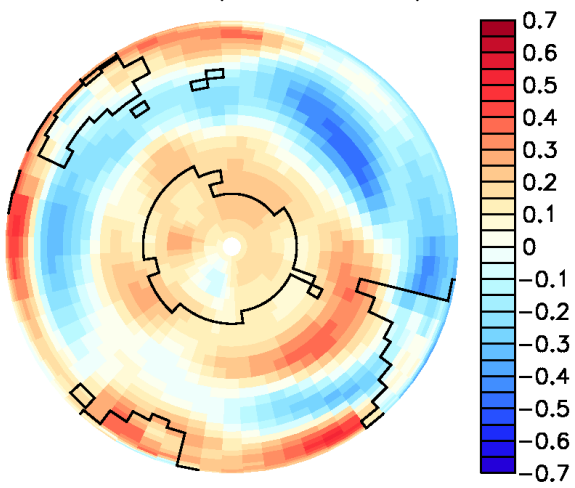

Member 3 (1851-2000)

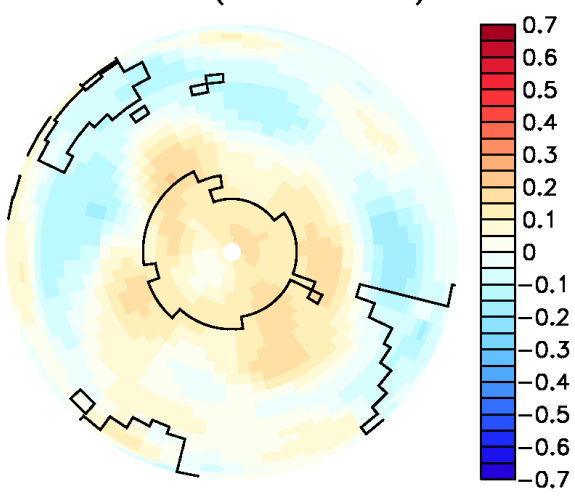

Member $3(501-2000)$

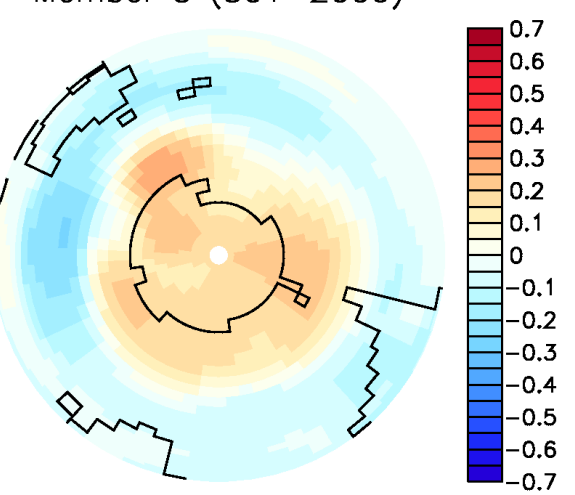

Figure S5. Correlation between precipitation at Law Dome and Southern Hemisphere mean sea level pressure for each member of OGSV. 


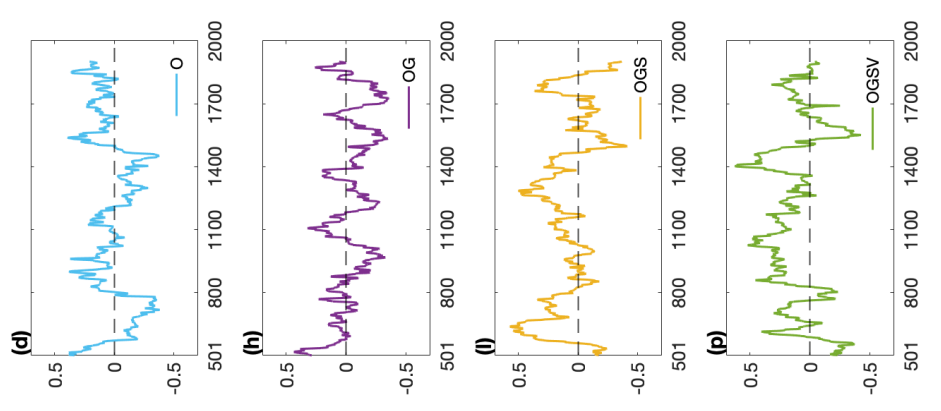

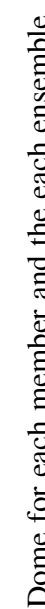

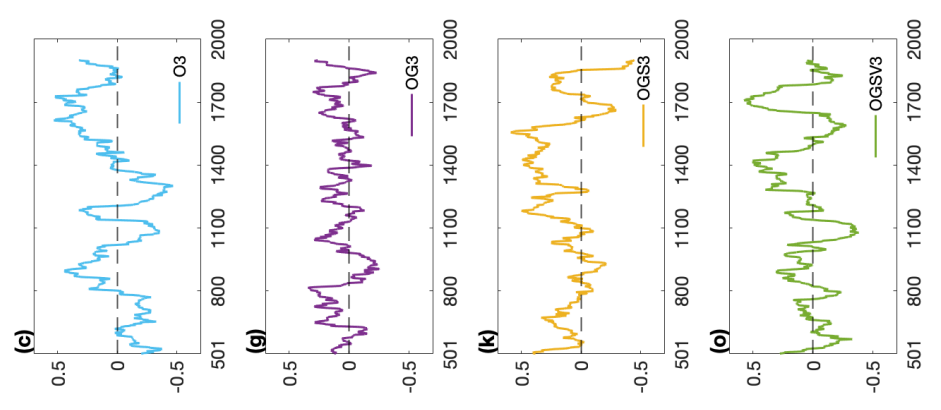

ঠ্ঠ
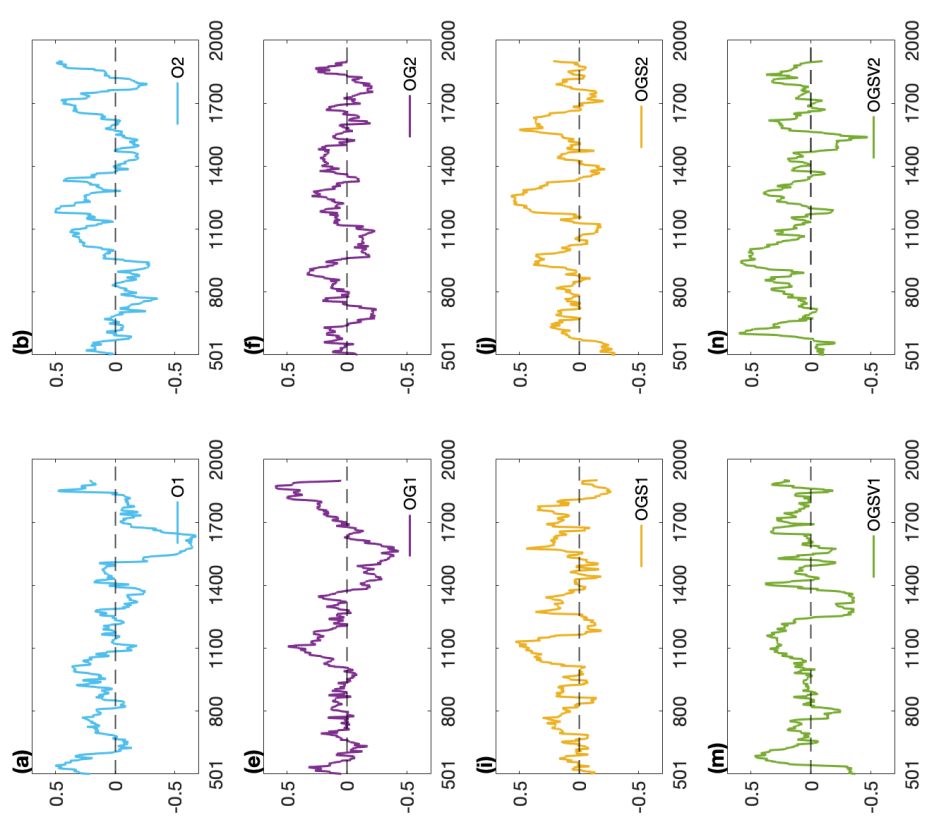

ио!ฺе|әдоо 6u!nund леәК-00 เ

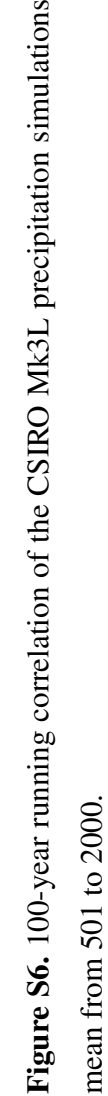


Figure S7 is the latest rainfall data from the Australian Government Bureau of Meteorology for the growing season in southwestern Australia from 1900 to 2020. The mean growing season rainfall in southwestern Australia from 1900 to 1970 is 564.97 $\mathrm{mm}$, from 1972 to 2014 is $481.26 \mathrm{~mm}$ and from 2016 to 2020 is $431.35 \mathrm{~mm}$. The drought continued during 2016-2020.

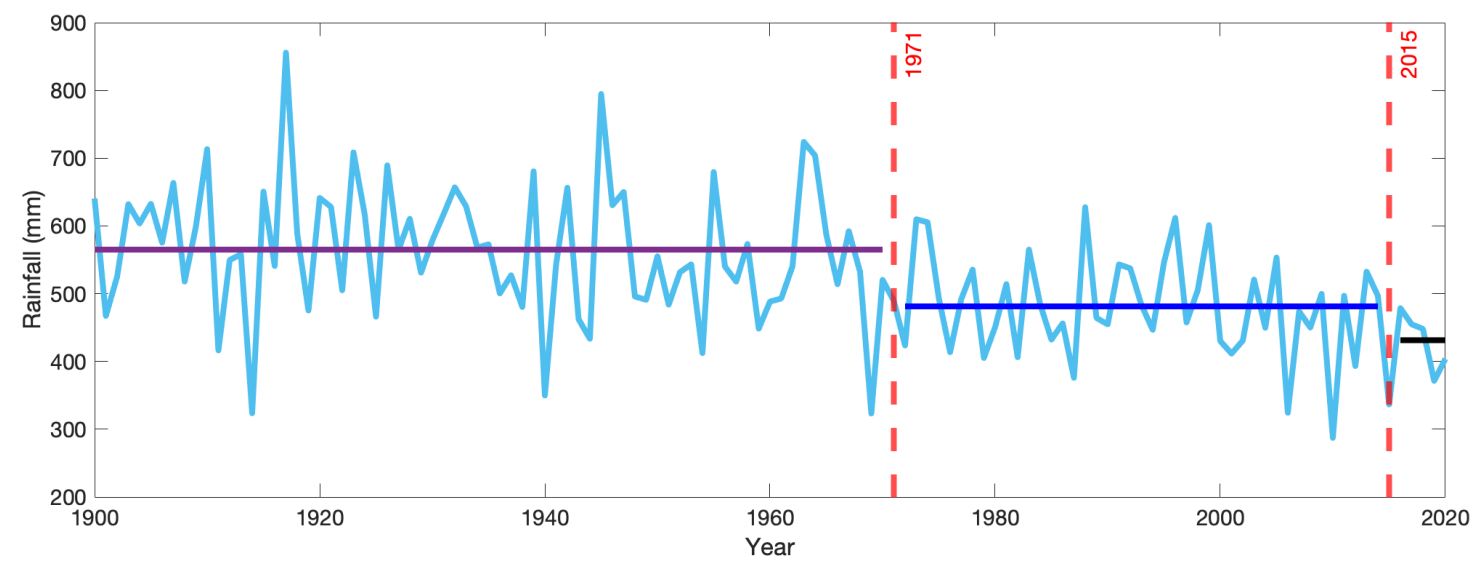

Figure S7. Time series of BoM rainfall in southwestern Australia at growing season from 1900 to 2020. 


\section{CUSUM analysis on each member of the model ensembles}

Table S5. The mean and standard deviation for each of the growing season rainfall time series from 501 CE to 2000 CE.

\begin{tabular}{ccc}
\hline Time series & Mean & Standard deviation \\
\hline Rainfall reconstruction & 406.00 & 22.61 \\
CONTROL1 & 220.59 & 17.39 \\
CONTROL2 & 223.75 & 17.16 \\
CONTROL3 & 221.96 & 17.40 \\
O1 & 223.21 & 17.95 \\
O2 & 224.12 & 16.79 \\
O3 & 226.60 & 17.47 \\
OG1 & 226.01 & 17.86 \\
OG2 & 224.21 & 16.95 \\
OG3 & 222.56 & 17.78 \\
OGS1 & 226.26 & 18.96 \\
OGS2 & 226.16 & 17.74 \\
OGS3 & 226.99 & 18.69 \\
OGSV1 & 226.98 & 19.08 \\
OGSV2 & 226.26 & 19.38 \\
OGSV3 & 225.63 & 17.97 \\
\hline & & \\
\hline & & \\
\hline
\end{tabular}




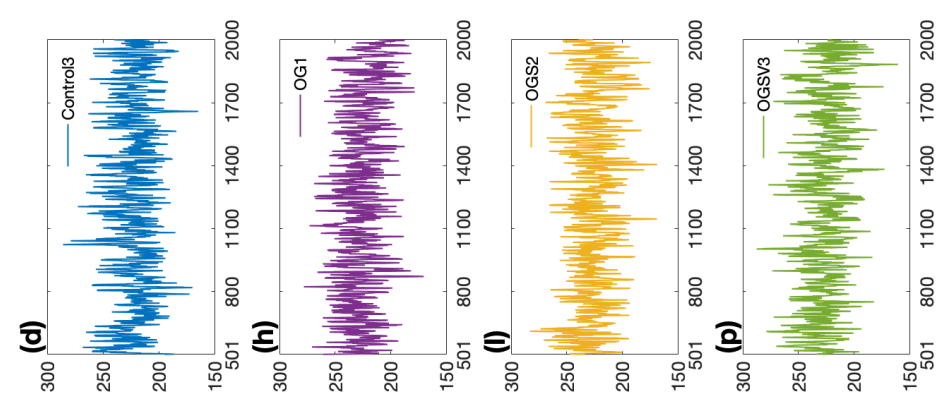

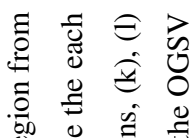

¿.0

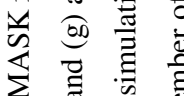
छ

$\Xi \hat{0} \frac{0}{0}$

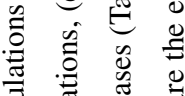

节 范

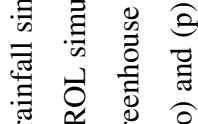

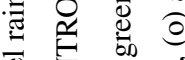

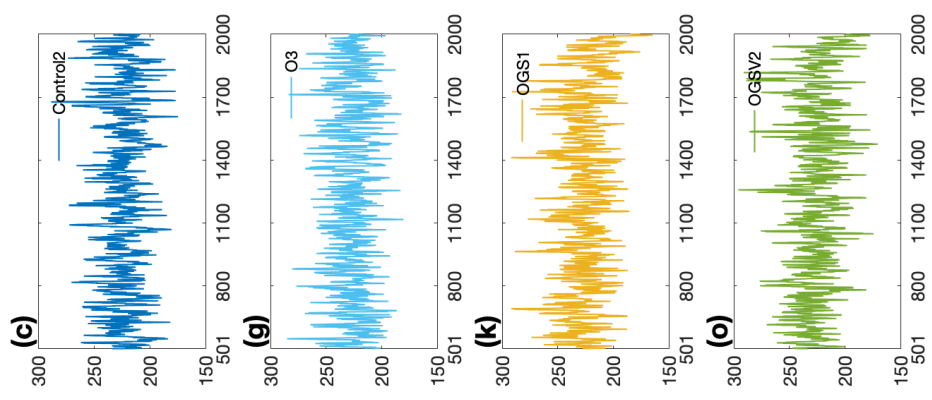

䙲 方

至

齐 离

이 छ ज

ป ड

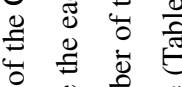

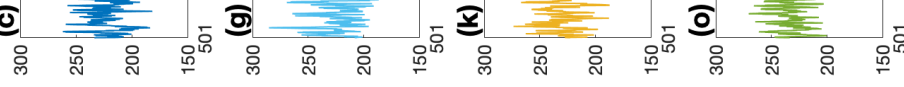

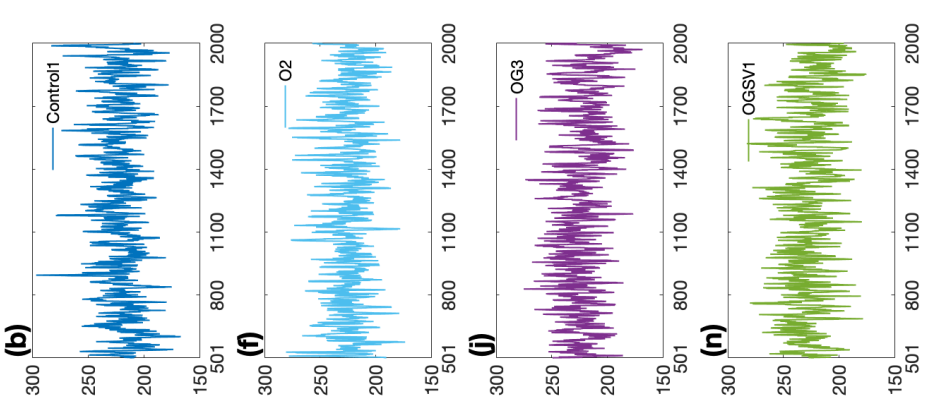

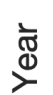

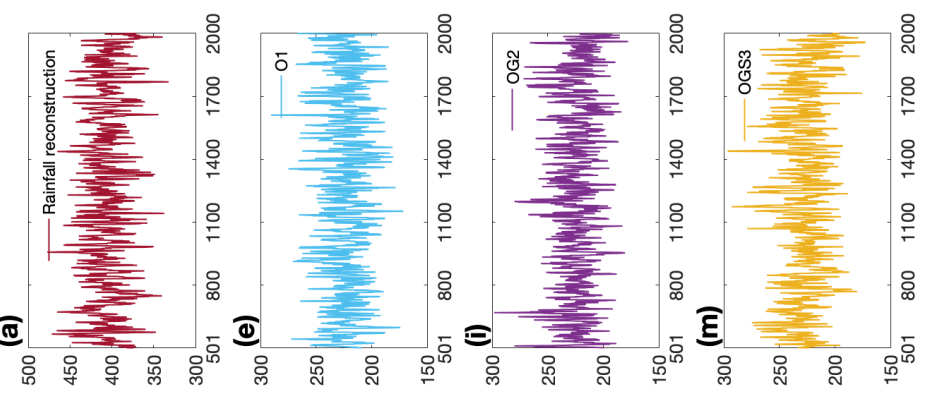

(mu) ॥еرu!̣ey

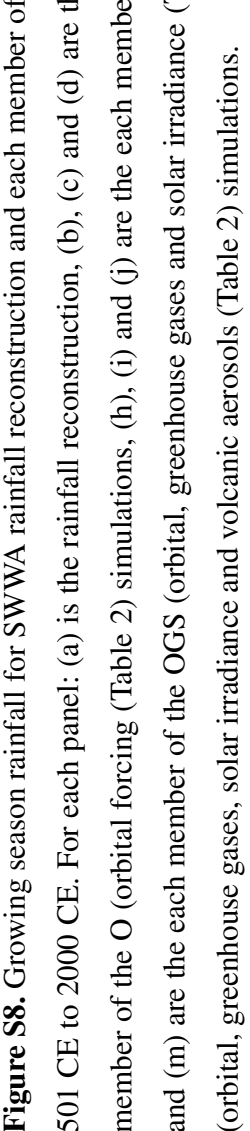




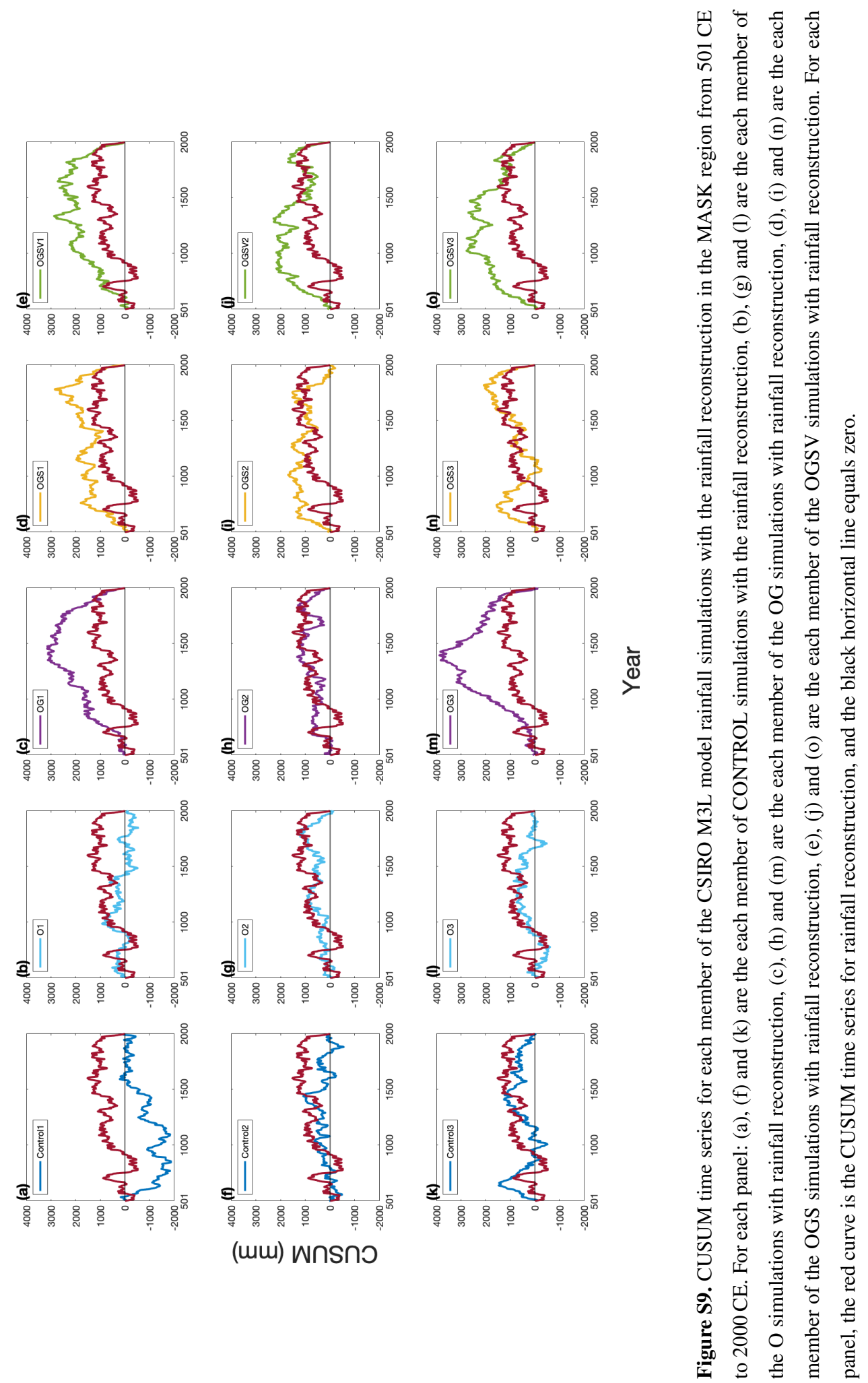




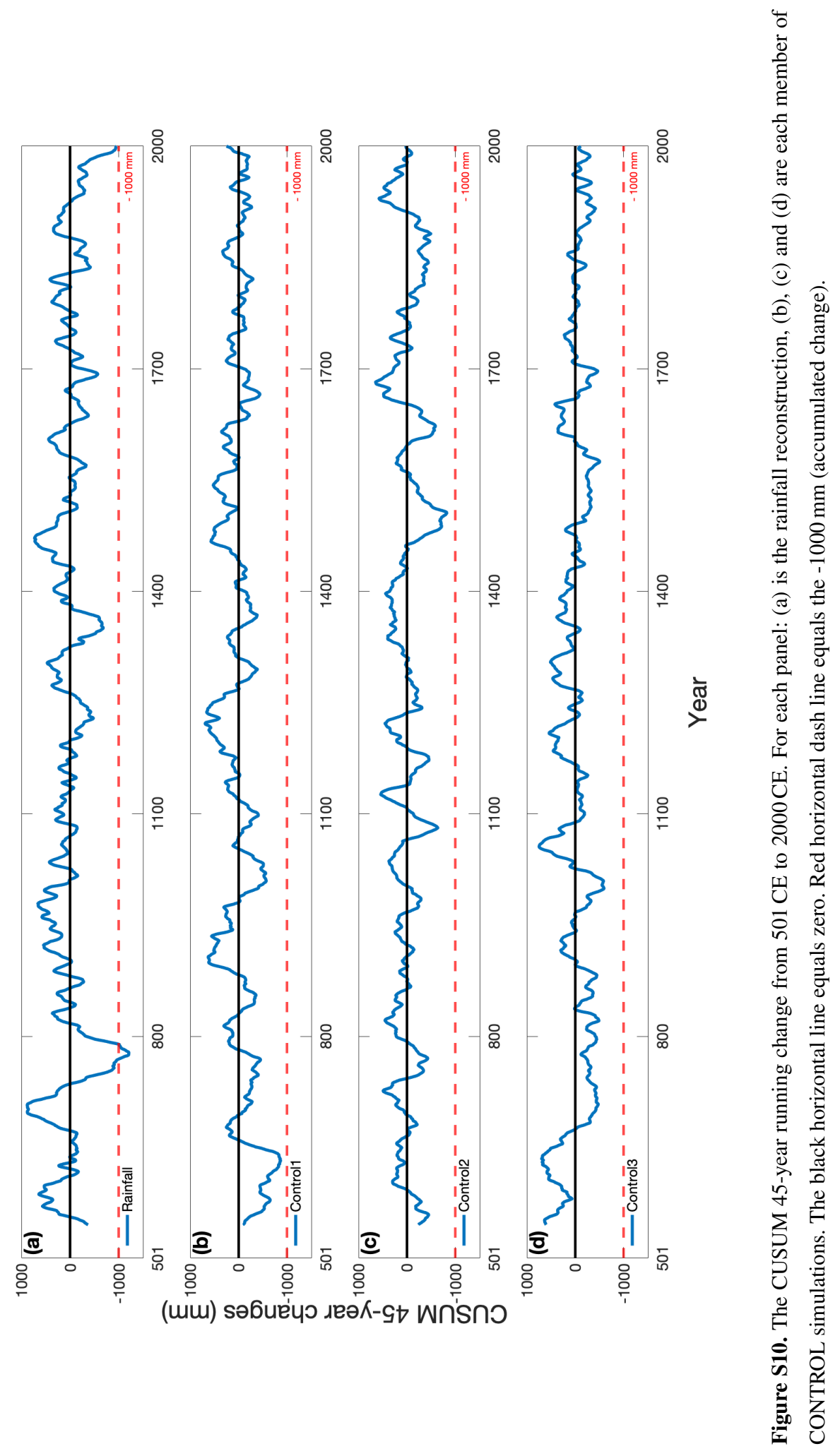




\section{References}

van Ommen, T. D. and Morgan, V.: Snowfall increase in coastal East Antarctica linked with southwest Western Australian drought, Nature Geoscience, 3, 267-272, 2010. 